\title{
La gestión estratégica de la información municipal. Análisis de temas, su tratamiento e irrupción en el Ayuntamiento de Elche (1995-2007)
}

Conchi Campillo

Universidad de Alicante

\section{Palabras clave}

Comunicación, municipal, información, estrategia, agenda temática.

\section{Resumen}

En el contexto local, los ayuntamientos como organización jurídica del municipio deben desarrollar una gestión suficiente de la información que influye o puede influir en la condición de los ciudadanos como administrados. No hacerlo de manera eficaz conlleva serios riesgos para su imagen, ya que serán los propios medios de comunicación a través de otras fuentes informativas (con intereses contrapuestos a los de la organización) los que, lanzando mensajes de diversa naturaleza, se conviertan en artífices de procesos de formación de opinión pública no controlados por la fuente objeto de información. En consecuencia, podemos afirmar que, dentro de la estrategia de comunicación externa de cualquier organización pública local, la función de mayor incidencia por su repercusión es la gestión de las relaciones informativas. Cuando los medios de comunicación ponen énfasis en ciertos temas o en ciertos aspectos de los asuntos municipales, obviando otros, construyen nuestra realidad social como ciudadanos. Este proceso de producción de noticias debe ser controlado por los responsables de las estructuras comunicativas de las entidades locales, implementando en su gestión profesional herramientas de evaluación que permitan establecer, reforzar, modificar o reorientar las políticas estratégicas informativas, sustentadas en los objetivos propios de la institución. 


\title{
The strategic management of the municipal information. Analysis of topics, its treatment and irruption in the Town hall of Elche (1995-2007)
}

\section{Keywords}

Communication, municipal, information, strategy, thematization.

\begin{abstract}
In the local context, the town halls like juridical organization of the municipality they must develop a sufficient management of the information that influences or can influence the condition of the citizens as administered. Not to do it in an effective way, he carries serious risks for his image, since they will be the own mass media across other informative sources (with interests opposed to those of the organization) those who, throwing messages of diverse nature, turn into process makers of formation of public opinion not controlled by the source object of information. In consequence, we can affirm that, inside the strategy of external communication of any public local organization, the function of major incident for his repercussion is the management of the informative relations. When the mass media put emphasis in certain topics or in certain aspects of the municipal matters, obviating others, they construct our social reality as citizens. This process of production of news must be controlled for the persons in charge of the communicative structures of the local authorities, implementing in his professional management tools of evaluation that they allow to establish, to reinforce, to modify or to reorientate the strategic informative policies sustained in the aims of the Institution.
\end{abstract}

\section{Autora}

Conchi Campillo [concepcion.campillo@ua.es] es licenciada en Ciencias de la Información por la Universidad Comuplutense de Madrid y doctora en Sociología por la Universidad de Alicante. Actualmente es profesora colaboradora del departamento de Comunicación y Psicología Social de la Universidad de Alicante. 


\section{Introducción}

En los contextos democráticos, una de las principales obligaciones de cualquier gobierno municipal es informar a los ciudadanos de aquellas decisiones o acuerdos alcanzados en la gestión político-administrativa que les influyen o pueden afectarles. Pero además, es necesario explicar y justificar a la ciudadanía el por qué de tales actuaciones y cuál va a ser la planificación del gasto público. Sólo así será posible que los administrados valoren positivamente las propuestas del proyecto administrativo; de ello depende que los responsables políticos obtengan de nuevo la confianza de los ciudadanos, cuando se celebren los próximos comicios electorales.

No desarrollar una gestión suficiente de la información que atañe a la entidad o no hacerlo de manera eficaz, conlleva serios riesgos para su imagen, ya que serán los propios medios de comunicación a través de otras fuentes informativas (con intereses contrapuestos a los de la organización) los que, lanzando mensajes de diversa naturaleza, se conviertan en artífices de procesos de formación de opinión pública no controlados por la fuente objeto de información. En consecuencia, podemos afirmar que, dentro de la estrategia de comunicación externa de cualquier organización pública, la función de mayor incidencia por su repercusión es, tal y como apuntan diversos autores, la gestión de las relaciones informativas; entendiendo como tales

«las actuaciones periodísticas encaminadas a seleccionar material propio para su suministro a los medios de comunicación y responder a las peticiones informativas internas y externas de la organización» (Ruiz Vivo, 2003: 39).

Las relaciones con los medios de comunicación social se erigen en premisa fundamental para propiciar acerca de las organizaciones públicas un estado de opinión favorable a sus objetivos y estrategias a medio y largo plazo.

\section{El poder de los medios de comunicación social}

La creencia asentada sobre el poder mediático procede de la ocupación por parte de éstos del espacio público como escenario en el que se plantean debates sobre cuestiones públicas. A través de los medios se expresa la voluntad y el hacer político, se reflejan las posturas de diferentes colectivos o movimientos organizativos, y se expresan las opiniones individuales de intelectuales, líderes de opinión y ciudadanos de a pie. Esto hace que el poder político, o mejor dicho, los poderes públicos, teman el tratamiento informativo o los comentarios vertidos sobre determinados asuntos que pueden ser especialmente conflictivos, comprometiendo seriamente la imagen pública de la institución o la de sus dirigentes. Contar con el favor del público es vital para que cualquier organización sea legitimada en el desarrollo de su función pública. Diezhandino (2007: 56) lo expresa de la siguiente forma «en un mundo alejado del respeto a ninguna 
autoridad moral, el dedo acusador de los medios representa una autoridad más temida que reconocida».

Autores como Neumann $(1973)^{1}$, Dennis (1991) o Gitlin $(2001)^{2}$ aseguran que el poder de los medios de comunicación no parte del propio mensaje lanzado sino de la acumulación o repetición de los mismos, cuando se focaliza un objeto determinado por parte de aquellos.

Tal acumulación de información en este ciclo ininterrumpido de producción y consumo de la información se caracteriza por no ser homogéneo sino diverso y plural, ya que la profusa existencia y gran variedad de medios de comunicación social condiciona los productos informativos elaborados para las audiencias.

Por otra parte, los medios de comunicación pueden ser utilizados como arma política. Diezhandino (2007) se refiere, en este sentido, al lado perverso de los medios cuando afirma que, la manipulación, intencionalidad o mentira de su discurso forma parte de un ecosistema social en el que los medios se han erigido como instrumentos útiles para la intoxicación informativa al servicio de determinados poderes (públicos o privados) con intereses manifiestos. Y de ahí, el temor que suscitan. No obstante, éstos sólo son uno de los elementos de tal ecosistema, en el cuál intervienen otros actores sociales o políticos que representan a una sociedad civil que se organiza para obtener resultados en clave política y que utilizan, en innumerables ocasiones, a los medios de comunicación para amplificar su causa.

\subsection{Interpretación de la realidad social y agenda política}

A través de la información periodística se interpreta permanentemente y de forma sucesiva la realidad social (Gomis, 1991; Armentia y Caminos, 1998). Este proceso consiste en presentar determinados hechos como acción discontinua para que la audiencia los capte y comprenda en toda su extensión. Permiten que nos adaptemos a la realidad que representan o actúan como un revulsivo necesario para adoptar posicionamientos enfocados a modificar aspectos de la realidad social.

En esta constante interpretación de la realidad, los medios se ven abocados a una selección permanente de las informaciones de las que disponen, bien a través de fuentes comunes como las agencias de información, gabinetes de prensa y comunicación, o propias, como los contactos personales de los propios periodistas del medio. De esta forma, los hechos, modelados convenientemente, se convierten en verdaderos productos informativos.

Por tanto, cuando los medios interpretan la realidad social como un conjunto de hechos, tratan de comprender algunos de los asuntos más significativos y tras-

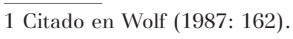

2 Citados en Diezhandino (2007: 43-44). 
cendentes para comunicarlos en forma de noticias o de cualquier otro género periodístico. A partir de esa redacción o configuración del hecho en cuestión, se produce un segundo nivel en el proceso de interpretación, orientado a formular, entre otros, todos los elementos formales destacados de la noticia como los textuales, el espacio redaccional o el tiempo destinado.

Si la realidad puede captarse de manera fragmentada en unidades independientes y completas llamadas hechos, y estas unidades pueden ser elaboradas y difundidas al público como noticias, tales hechos trascendentes representan la interpretación de la realidad social como mecanismo para activar las conciencias colectivas. Cumplen un papel esencial para que los miembros de una colectividad reflexionen, establezcan intercambios comunicativos y, en consecuencia, intervengan en un aspecto concreto de su realidad para propiciar ciertos cambios sociales.

Para llevar a cabo esta función, la actividad desarrollada por el gabinete de comunicación de cualquier institución pública es fundamental. Utiliza instrumentos tales como convocatorias, para informar de la celebración de un acontecimiento puntual; comunicados, que ofrecen información sobre los distintos temas noticiosos de interés general; ruedas de prensa, cuando se requiere la presencia física de los periodistas en el momento de ofrecer información sobre un evento, hecho o informe importante; declaraciones, entrevistas, exclusivas o cualquier otro formato que permita alcanzar los objetivos informativos establecidos por los responsables de la organización.

En consecuencia, la organización pública se erige como una fuente de información fiable y accesible para los medios de comunicación social que solicitan atención o demandan respuestas concretas sobre asuntos, temas o cuestiones consideradas de interés para sus públicos.

De la misma forma que sucede en el contexto social, económico o cultural, en el ámbito político, cualquier hecho trascendente que se produzca (ya sea previsible o no) va a llamar poderosamente la atención de los medios de comunicación y se harán eco de sus aspectos más significativos. Por otra parte, las propias organizaciones públicas estarán interesadas en que los medios de comunicación reflejen iniciativas, proyectos, actuaciones o programas que se enmarcan en sus políticas estratégicas.

La agenda política se traslada así a la agenda mediática. De manera secuencial, el medio ofrece una información seleccionada e interpretada que dosifica y en la que enfatiza determinadas cuestiones, ofreciendo un encuadre o marco de referencia que permita a los ciudadanos comprender toda la dimensión y complejidad de un fenómeno concreto.

Esta simbiosis permanente entre medios de comunicación y organizaciones públicas, tiende a mantenerse de forma equilibrada a través de una gestión 
profesionalizada de la unidad administrativa responsable de las relaciones informativas.

\subsection{Tematización mediática y opinión pública}

En una sociedad tan sumamente compleja como la actual, en la que, en el ámbito público se manifiestan una gran variedad de intereses (en ocasiones, contrapuestos con los privados) y en la que entroncan experiencias directas personales e iniciativas colectivas de finalidades diversas, no es posible alcanzar el consenso respecto a determinados temas, únicamente mediante procesos de opinión pública que son resultado de la discusión libre entre los individuos (Abril, 1997). Es a partir de la selección y jerarquización de los temas insertados de manera continuada en los medios, cuando verdaderamente se configuran estados de opinión pública.

Tal y como advierte D'Adamo (2007), existe una gran variedad de concepciones que se refieren al fenómeno de la opinión pública: algunos autores se refieren a ella como el sumatorio de lo que opinan los individuos que integran una comunidad o un segmento poblacional sobre un tema en cuestión; otros la abordan, simplemente, como la opinión que expresan individuos determinados, una minoría o bien los grupos de referencia dentro de la sociedad. También encontramos ciertas aportaciones que identifican el proceso como aquello que reproducen los medios de comunicación a partir de la agenda pública de temas, y equiparan el concepto de opinión pública al de opinión publicada. Pero además, existe, dentro de la contextualización del fenómeno, un posicionamiento relacionado con los escenarios o espacios públicos donde se configuran las opiniones expresadas por los ciudadanos.

Ante tal circunstancia, conviene aclarar que las opiniones colectivas surgen a partir de procesos que se identifican con fenómenos sociales en los que intervienen múltiples factores relacionados, por una parte, con la comunicación generada por el sistema político ${ }^{3}$; por otra, con las características propias del entorno en el que se desarrollan tales procesos comunicativos públicos.

De esta forma, la opinión pública queda identificada como una estructura cognitiva de temas institucionalizados por parte del sistema político, a partir de la cuál son los medios de comunicación social los que establecen una valoración de relevancia según la selección y jerarquía que establecen respecto a ellos.

«los medios de comunicación ejercen una actividad selectiva otorgando pertinencia a unos temas y restándosela a otros. Los temas configuran ámbitos de sentido compartido socialmente, y sirven por ello para fundar o regular el consenso social» (Abril, 1997: 277).

La influencia que ejercen los medios de comunicación social sobre los procesos de formación de opinión pública ya ha sido suficientemente demostrada en innumerables estudios empíricos. Aportaciones como la formulación de la hipótesis

3 Instituciones, partidos políticos o la administración. 
del establecimiento de la agenda temática ${ }^{4}$ (agenda setting) efectuada por McCombs y Shaw (1972), así como conceptos como la prominencia (priming) y el encuadre de los objetos (framing) han contribuido a ello, abriendo un amplio y diverso ámbito exploratorio sobre la investigación de los efectos acumulados de los medios de comunicación en las audiencias.

Y así, la hipótesis del establecimiento de agenda o tematización mediática se basa en la capacidad de los medios para establecer una delimitación de temas sobre los que la audiencia va a pensar o va a establecer procesos de discusión pública (D’Adamo, 2007) ${ }^{5}$. Al captar la atención de sus audiencias a partir de tales procesos de selección instalan en la agenda pública los temas de mayor importancia o jerarquía, aproximando a la ciudadanía a una determinada realidad social.

Nos referimos, por tanto, a la agenda temática como el conjunto de temas (o issues) que un medio de comunicación recopila diariamente con la intención de planificar de forma genérica su cobertura informativa en un periodo determinado.

Un issue o tema puede definirse a nivel conceptual como «un problema social, a menudo conflictivo, que ha recibido cobertura informativa» (Dearing y Rogers, 1996: 2$)^{6}$. Y representan, dentro del establecimiento de la agenda, su primera dimensión.

Pero, además, los medios de comunicación no sólo sitúan o prestan atención a ciertos temas del entorno, sino que les otorgan significado. Así, al poner énfasis en ciertos temas o en ciertos aspectos de los asuntos, obviando otros, construyen nuestra realidad social. Este proceso de producción de noticias se convierte en una variable fundamental en la construcción de las imágenes mentales de nuestro mundo; la experiencia personal que aportan los individuos sobre el objeto en cuestión, a partir de este proceso de comunicación, constituye, junto con la anterior, la segunda variable que condiciona el efecto de la llamada agenda setting.

La evolución de esta teoría nos sitúa en un marco conceptual mucho más amplio y profundo que el ya establecido en sus orígenes intelectuales. La agenda setting no se refiere sólo a los temas sino que incluye además las imágenes y las pers-

\footnotetext{
4 Es a finales de los años 60 y principios de los 70 cuando se produce un relevante punto de inflexión en la investigación de la influencia de los medios de comunicación de masas sobre la opinión pública; quedando superadas, de esta forma, teorías como la aguja hipodérmica, la vinculada a los efectos persuasivos y a los efectos limitados (Wolf, 1987). En esta nueva fase se incide, por una parte, en el poder que ostentan los medios de comunicación cuando, a través de la rutinas periodísticas focalizan su atención en determinados temas o asuntos, desatendiendo otros; por otra, en el marco de referencia o de interpretación que se establece para configurar la identidad propia de tales objetos. Es decir: no sólo se establece a partir de la selección de los temas por parte de los medios "sobre qué pensar", sino que la propia estructura, orientación y el grado de complejidad con que se abordan tales temas, condiciona el marco de interpretación que hace la audiencia acerca de ese objeto.

5 Véase además: Wolf (1987), Monzón (1990, 2006), Gomis (1991), Abril (1997), Armentia y Caminos (1998).

6 Citado en D'Adamo (2007: 123).
} 
pectivas: tiene que ver con cómo se produce la transferencia de la prominencia de objetos cognitivos en su primera y segunda dimensión.

Y así, cada medio representa un espacio concreto dentro del universo informativo, que se materializa en periodos puntuales (diario, semanario, etc.). En este proceso interpretativo y jerárquico, los medios de comunicación orientan la atención del público hacia determinados temas a partir de la consideración general de qué es lo que a la audiencia del medio en cuestión puede interesarle más.

Tal proceso selectivo conlleva el que cada medio cree su propia realidad; y en este sentido, es obvio que el contenido de una «agenda temática» no es una operación ni inocente ni casual (Armentia y Caminos, 1998). La reiteración de temas desempeña un papel de auténtico goteo social; de manera que, el público tiene permanentemente presentes aquellos temas que los medios de comunicación exponen reiteradamente y, junto con la influencia de sus propias experiencias directas y otros factores de su ecosistema social, es posible que acaben adoptando la opinión que preconizan determinados medios.

\section{Gabinetes de comunicación y Administración Municipal}

En un contexto local sumamente dinámico, en el que intervienen en la configuración de la imagen organizacional diferentes agentes como los medios de comunicación social, los líderes de opinión, movimientos asociativos y tejido social, ciudadanos individuales y plurales, además de diferentes organizaciones y niveles administrativos, los ayuntamientos tienen que adaptarse a nuevas circunstancias y exigencias sociales, estableciendo o propiciando procesos de comunicación pública que permitan mostrar (y demostrar) a los ciudadanos que constituyen el epicentro de la actuación administrativa.

Los gabinetes de comunicación municipal constituyen, en la actualidad, auténticas direcciones de comunicación: son fuentes organizadas estables que cuentan con estructuras definidas para desarrollar, como subsistemas organizacionales, funciones de comunicación pública. Se sitúan, dentro de la organización municipal, en los niveles superiores ${ }^{7}$; de esta forma, no sólo queda de manifiesto el compromiso por parte de la institución con las políticas de comunicación pública, sino que los máximos responsables políticos y administrativos de las áreas de gestión comparten un referente común a la hora de desarrollar iniciativas, implantar proyectos, desarrollar estrategias relacionales y políticas comunicativas.

Diversos autores se han aproximado a estas unidades administrativas, proponiendo definiciones a partir de las funciones básicas que desempeñan, para Ramírez (1995: 27) los gabinetes de comunicación son:

7 Tal y como apuntan autores como Álvarez y Caballero (1999) o Bel Mallén (2004) al referirse a la ubicación de las direcciones de comunicación en organizaciones de diversa índole. 
«las fuentes activas, organizadas y habitualmente estables de información que cubren las necesidades comunicativas tanto internas como externas de aquellas organizaciones y/o personas de relieve que desean transmitir una imagen positiva a la sociedad influyendo de esta forma en la opinión pública».

Se convierten así, según Castillo y Almansa (2001: 383), en:

«la instancia que debe dirigir, gestionar, planificar y coordinar las actividades de comunicación que desarrolla una organización. El gabinete no sólo ha de realizar las acciones emprendidas y planificadas en su seno, sino que también posee una función de asesoramiento en comunicación en el resto de departamentos o secciones de la organización. A su vez cabe destacar que las funciones comunicativas que debe desarrollar implican a las externas pero, asimismo, a las internas».

Para Villafañe (1999: 221):

«los gabinetes llevan a cabo programas de comunicación corporativa, que tienen como objeto la consideración de una imagen positiva de la organización entre determinados públicos que tienen una importancia estratégica para ésta».

Y Almansa (2005: 123-124) propone la siguiente definición:

«el gabinete de comunicación es una estructura organizada, con dependencia directa de la alta dirección, que coordina y cohesiona todas las acciones de comunicación (internas y externas) para crear, mantener o mejorar la imagen de la organización ante todos sus públicos. Es una estructura organizada porque tiene establecidas unas formas de actuación y de relación».

Lo cierto es que, durante las últimas tres décadas, por una parte, se ha avanzado mucho en la profesionalización de los gabinetes de comunicación municipales; y por otra, se ha producido una evolución constante en los medios de comunicación, sus técnicas, formatos y procedimientos de trabajo. Díez Lobo (2004), director de comunicación de la Federación Española de Municipios y Provincias (FEMP), apunta, en este sentido, dos circunstancias que han influido sustancialmente en la consolidación de los gabinetes: una mayor profesionalización de la propia función pública y el hecho de que, en la actualidad, los representantes políticos y directivos municipales de las estructuras (centralizadas y no centralizadas) hayan interiorizado una cultura diferente de la gestión de la comunicación informativa, utilizando recursos y canales absolutamente novedosos y eficientes.

Para planificar y gestionar todas las estrategias y políticas comunicativas del ente municipal, estas unidades o departamentos administrativos trabajan con un doble propósito: dar a conocer a los diferentes segmentos de la ciudadanía al ente municipal, como organización que presta servicios y desarrolla actividades de diferente índole; y, por otra parte, propiciar políticas de proximidad y participación ciudadana a través de procesos de comunicación bidireccional: ambos, se plantean con el objetivo final de consolidar una imagen positiva que redunde en la credibilidad y legitimación de la organización pública.

Las relaciones con los medios de comunicación siguen siendo consideradas como el rol esencial a desarrollar por parte de la dirección de comunicación municipal (Lucas, 1997; Castillo y Almansa, 2001; Almansa, 2004, 2005); no obstante, se constata cómo dicha función, anclada en los orígenes de los gabinetes, ni es 
la única ni puede desarrollarse, en el contexto actual, sin el respaldo de otras actividades $^{8}$ enfocadas a cubrir las necesidades específicas de la interacción comunicativa-relacional entre administración y administrados.

\section{Objetivos de investigación y metodología}

Esta investigación se enmarca en el municipio de Elche como contexto local. A través de este estudio, pretendemos analizar cuáles han sido los temas principales, relativos a los diferentes ámbitos relacionados con la dinámica municipal que han ido configurando la agenda temática durante las legislaturas 1995-1999, 1999-2003 y 2003-2007, identificando qué temas ${ }^{9}$ relacionados con la gestión y la política municipal se presentan con mayor grado de recurrencia, su naturaleza positiva, negativa, neutra o ambivalente ${ }^{10}$ como información en prensa escrita, estableciendo, a partir de esta segunda variable, las relaciones existentes con su irrupción, según sea fortuita, programada o previsible ${ }^{11}$. Para ello, se plantean dos hipótesis iniciales:

1. Existen temas relacionados con la gestión municipal que tienen una presencia mediática relevante y que coinciden de una legislatura a otra.

8 Nos referimos especialmente a la publicidad institucional, la gestión de relaciones institucionales, la participación ciudadana, la atención personalizada a través de las OMACs (oficinas municipales de atención al ciudadano), la comunicación 2.0 y la gestión de acontecimientos especiales, orientados a los ciudadanos como públicos internos, o bien dirigidos a públicos (potenciales) externos, con una notable o trascendente proyección mediática para el municipio.

9 Aperturas, asesoría jurídica, bienestar social, consumo, contratación, cooperación al desarrollo, cultura, deporte, educación, fiestas, fomento, futurelx (plan estratégico), hacienda, juventud, medio ambiente, oficina municipal de atención al ciudadano, partidos políticos, pedanías, rr. institucionales, rr. externas, rr.hh., organización y calidad, seguridad ciudadana, servicios y mantenimiento, tráfico, turismo, urbanismo, varios. Temas identificados a partir de los descriptores del Reglamento de Organización Administrativa del Ajuntament d’Elx (2003-2007).

10 Nos referimos a noticias negativas, ambivalentes, neutras o positivas como cuatro categorías diferentes que representan la naturaleza de los temas que hemos apuntado: las dos primeras representan la información que distorsiona los objetivos de la organización municipal, ya sea por su carácter eminentemente negativo, perjudicando seriamente la imagen de la Institución y sus dirigentes políticos, o ambivalente, cuando existen en ella discursos enfrentados entre el emisor institucional y los implicados: afectados directos, sus representantes o los partidos de la oposición. Las dos categorías restantes se sitúan en el polo opuesto: nos referimos a aquellas noticias neutras y positivas que permiten identificar, bien a aquellas noticias que no suponen menoscabo alguno en la gestión municipal (por tanto poseen un efecto neutro) o que son una clara manifestación de gestión positiva por parte del Ayuntamiento ilicitano.

11 La irrupción de la información se establece a partir de la clasificación propuesta por Casasús (1988: 134-139). Así, podemos identificar noticias de carácter fortuito que tratan de un hecho imprevisto o suceden sin que se haya pensado en tal circunstancia: irrumpen intempestivamente y su mayor o menor carácter noticioso vendrá determinado por el grado de trasgresión que produzca sobre el discurrir normal de los acontecimientos. Otros acontecimientos son previsibles, y adquieren forma en aquellas informaciones que, a pesar de una cierta apariencia fortuita, tratan de hechos cuya producción o manifestación era susceptible de ser conjeturada con anticipación. Es un tipo de información que se basa en la previsión de que algo va a suceder a consecuencia de la detección de unos síntomas que se ven o se observan. Tienen que ver con las rutinas, los procesos y dinámicas habituales de la gestión de lo municipal; de manera que, muchas de estas noticias son consecuencia directa de informaciones editadas días anteriores. La tercera categoría, se corresponde con las noticias que surgen a partir de la información programada: son aquellas cuyo desarrollo está previsto con antelación y cuya presentación alcanza unos índices de probabilidad muy altos. Nos referimos a hechos que pueden ser excepcionales en el tiempo o que se presentan reiteradamente en periodos temporales diferentes y que obligan a preparar, con suficiente antelación, un plan de trabajo para su cobertura informativa en el momento en que tal hecho se produce. 
2. La irrupción (fortuita, previsible y programada) de las noticias municipales está directamente relacionada con el tratamiento (positivo, negativo, neutro o ambivalente) de las mismas.

Mediante el análisis de contenido, obtendremos una descripción analítica de los hechos informativos que nos permita, a través de un proceso inferencial, interpretar los datos obtenidos a partir de la codificación de diferentes variables. De esta forma, se pretende que dicho análisis supere la vertiente simplemente descriptiva de lo cuantitativo, para alcanzar ciertas cotas de interpretación basadas en lo cualitativo.

Numerosos autores recogen la descripción de este método; entre ellos, Bardin (1986: 7) que se refiere al mismo como «un conjunto de instrumentos metodológicos aplicados a discursos (contenidos y continentes) muy diversos». Y añade, además, como premisas fundamentales, la descripción analítica del contenido de los mensajes y la inferencia, como deducción lógica de conocimientos relativos a las condiciones de producción y objetivo fundamental del análisis de contenido.

En este mismo sentido, Krippendorf (1990) define el análisis de contenido como:

«Una técnica de investigación destinada a formular, a partir de ciertos datos, inferencias reproducibles y válidas que pueden aplicarse a su contexto. El análisis de contenido es una técnica de investigación para formular inferencias identificando de manera sistemática y objetiva, ciertas características especificadas dentro de un texto» (1990: 28, 31-32).

Concibe por tanto este método, no sólo para investigar el significado simbólico de los mensajes, sino también para desarrollar la formulación de inferencias. La descripción analítica consistiría, por tanto, en la descomposición objetiva de las unidades de codificación o registro; mientras que la inferencia representa el proceso que nos va a permitir establecer las relaciones existentes entre los datos obtenidos y lo que significan dichos datos, tomando como referencia los objetivos de nuestra investigación.

Para ello, identificamos como unidades de contexto un número determinado de ejemplares de este diario que serán utilizados para establecer un universo o corpus de noticias de entre las cuáles se selecciona una muestra, suficientemente representativa, que garantice el análisis de los datos de forma fiable.

Si partimos del número total de periódicos durante los doce años correspondientes a las tres legislaturas a analizar, inicialmente nos encontraríamos con un total de 4.380 periódicos, que representan las diferentes unidades de contexto; a partir de ellas determinamos el corpus o universo.

Diseñamos una herramienta metodológica a partir de las variables tema, tratamiento e irrupción que nos permita codificar una muestra representativa, dentro de las unidades de contexto que forman parte de nuestro marco de investigación. 
Imagen 1. Formulario de introducción y análisis de datos

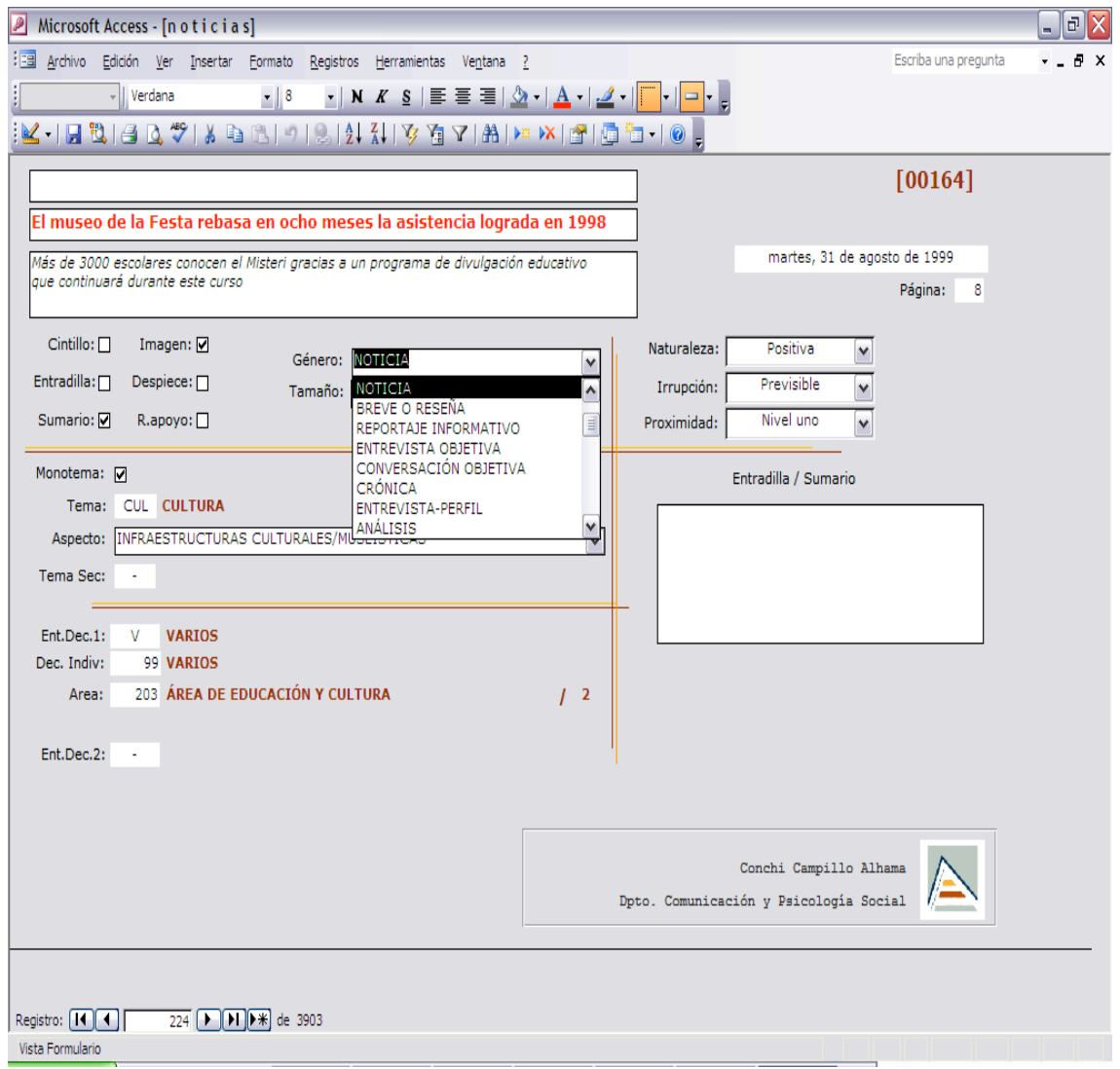

Tras una exploración previa a través del archivo documental del gabinete de prensa del Ayuntamiento de Elche, observamos que la media de hechos informativos municipales que se traducen diariamente en noticias, es de cinco. Nos encontramos, por tanto, ante un universo de 21.900 noticias que representan un universo finito. Según criterios estadísticos de inferencia probabilística, se aplica un nivel de confianza del $95,5 \%$ y un margen de error del $2 \%$; aplicando la siguiente fórmula, obtenemos la muestra mínima representativa de noticias del diario Información en su edición local para realizar el análisis de contenido sobre tematización municipal a partir de 2.243 noticias. Dividimos la muestra resultante entre cinco noticias por ejemplar y obtenemos un total de 448 periódicos como unidades de contexto, realizando una afijación o distribución muestral estratificada y sistemática por legislaturas, años y semanas. 


\section{Resultados de investigación}

La gestión municipal de los tres periodos analizados se contextualiza a través de veintisiete temas, a través de los cuáles se identifica la gestión político-administrativa del Ayuntamiento de Elche durante tres legislaturas consecutivas, a través de las diferentes concejalías como unidades centralizadas y los organismos autónomos o empresas municipales como estructuras descentralizadas.

\section{Gráfico 2. Distribución de los temas municipales}

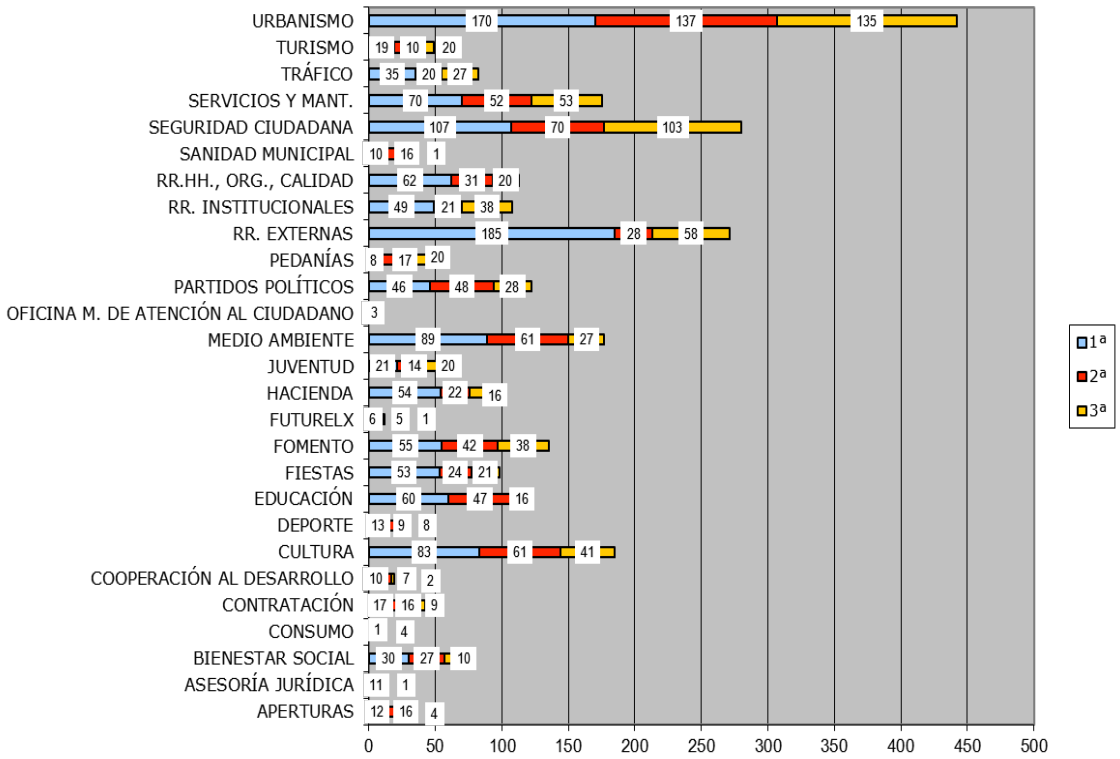

A partir del gráfico anterior, se observa que, de manera conjunta en las tres legislaturas, urbanismo es el tema municipal que adquiere una mayor presencia en las noticias analizadas, seguido de seguridad ciudadana, relaciones externas, cultura, medio ambiente, servicios y mantenimiento. Tales categorías representan los valores más destacados sobre todo el periodo analizado: son asuntos que aparecen de manera recurrente a lo largo de cada una de las tres legislaturas.

En la primera legislatura, irrumpen los temas relacionados con las relaciones externas, establecidas por la institución municipal para desarrollar, en colaboración con otras instituciones, administraciones públicas, entidades y asociaciones ciudadanas, diversos programas, planes de actuación e iniciativas de interés general; le siguen urbanismo, seguridad ciudadana y medio ambiente. 
Durante la segunda legislatura, destacan los temas de urbanismo que crece progresivamente desde la primera hasta la tercera legislatura. Así mismo, seguridad ciudadana, medio ambiente y cultura se presentan también como temas relevantes.

En la tercera, seguimos asistiendo a un despegue notable de la información relacionada con la gestión urbanística, centrada en infracciones, programas y la gestión del desarrollo urbano e infraestructuras, entre otros asuntos. Le siguen los temas de seguridad ciudadana y relaciones externas, irrumpiendo, en este periodo, la información relativa a servicios y mantenimiento de la vía y los espacios públicos.

La segunda variable que hemos planteado está directamente vinculada con el tratamiento informativo de los temas municipales, tal y como se puede observar en el siguiente gráfico.

\section{Gráfico 3. Naturaleza de la información municipal (1995-2007)}

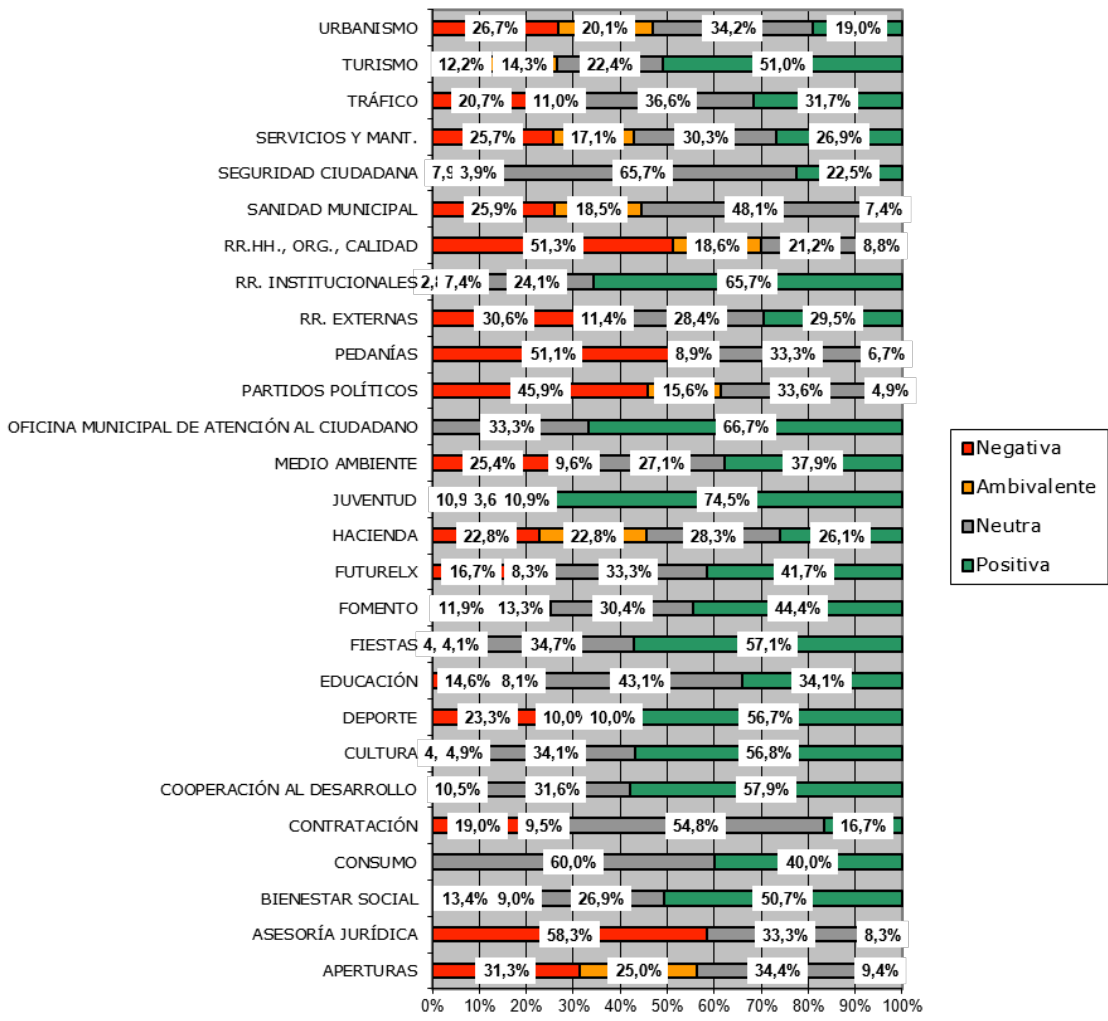


Las cuestiones reflejadas en el medio local sobre RR.HH., organización y calidad, se presentan de forma conjunta en los tres periodos analizados (con un $69,9 \%$ ), bien con un marcado carácter negativo o en estructuras discursivas ambivalentes en las que aparecen versiones contrapuestas de los hechos por parte de la fuente municipal frente a los individuos afectados, sus colectivos y representantes sindicales; por otro lado, las informaciones acaecidas sobre la gestión interna y el funcionamiento de las agrupaciones políticas locales que configuran la Corporación municipal (con un 61,5\%) afecta a su imagen como organizaciones y, por extensión, a la propia imagen del Ayuntamiento como institución pública. A estos dos temas, se suma la circunstancia de que la gestión político-administrativa en las pedanías municipales, como entes descentralizados, refleja las tensiones y conflictos a los que se ha visto enfrentado el equipo de gobierno municipal durante las tres últimas legislaturas (con un 60\%).

\section{Gráfico 4. Irrupción de los temas municipales (1995-2007)}

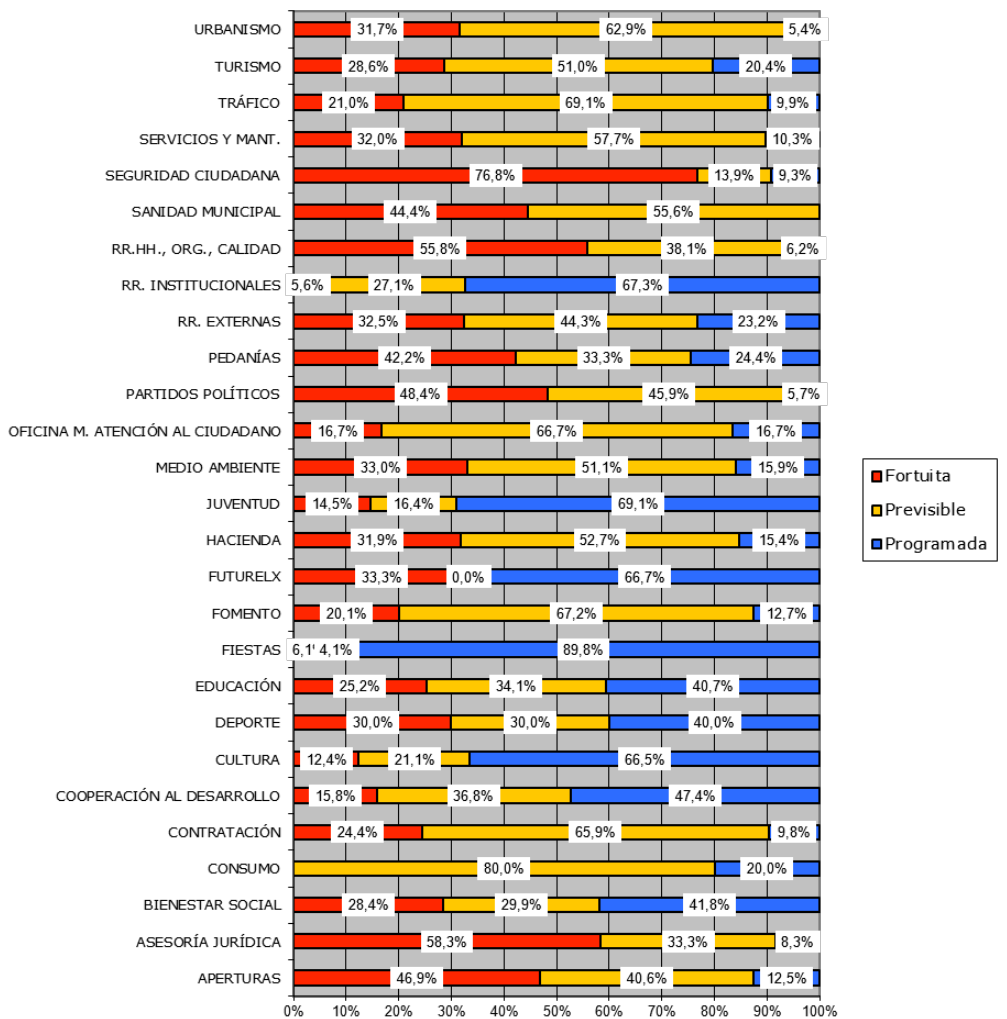


Siguiendo con este análisis, destacan, como informaciones fortuitas las que abordan temas como: seguridad ciudadana $(76,8 \%)$, asesoría jurídica $(58,3 \%)$, recursos humanos, organización y calidad $(55,8 \%)$, así como las relaciones internas de los partidos políticos con representación local $(48,4 \%)$, aperturas $(46,9 \%)$ y pedanías $(42,2 \%)$.

En el extremo contrario, observamos cómo el mayor índice de noticias programadas, se corresponde con fiestas $(89,8 \%)$, juventud $(69,1 \%)$, relaciones institucionales $(67,3 \%)$, el plan estratégico futurelx $(66,7 \%)$ y cultura $(66,5 \%)$.

Por su parte, los temas relacionados con gestión municipal de carácter previsible, aparecen en noticias de largo recorrido; muchas de ellas obedecen a un desarrollo secuencial de un determinado hecho: son noticias que, consecuentemente, se retroalimentan de las noticias anteriores relacionadas con ese mismo asunto o bien emergen a partir del desarrollo secuencial de determinadas competencias municipales. Si observamos el gráfico anterior, consumo $(80 \%)$, tráfico $(69,1 \%)$, fomento $(67,2 \%)$, contratación $(65,9 \%)$ y urbanismo $(62,9 \%)$, destacan como valores más significativos en esta categoría.

En los tres gráficos siguientes, podemos observar la relación existente entre la irrupción de los temas municipales y su tratamiento informativo.

\section{Gráfico 5. Temas fortuitos y naturaleza de las noticias (1995-2007)}

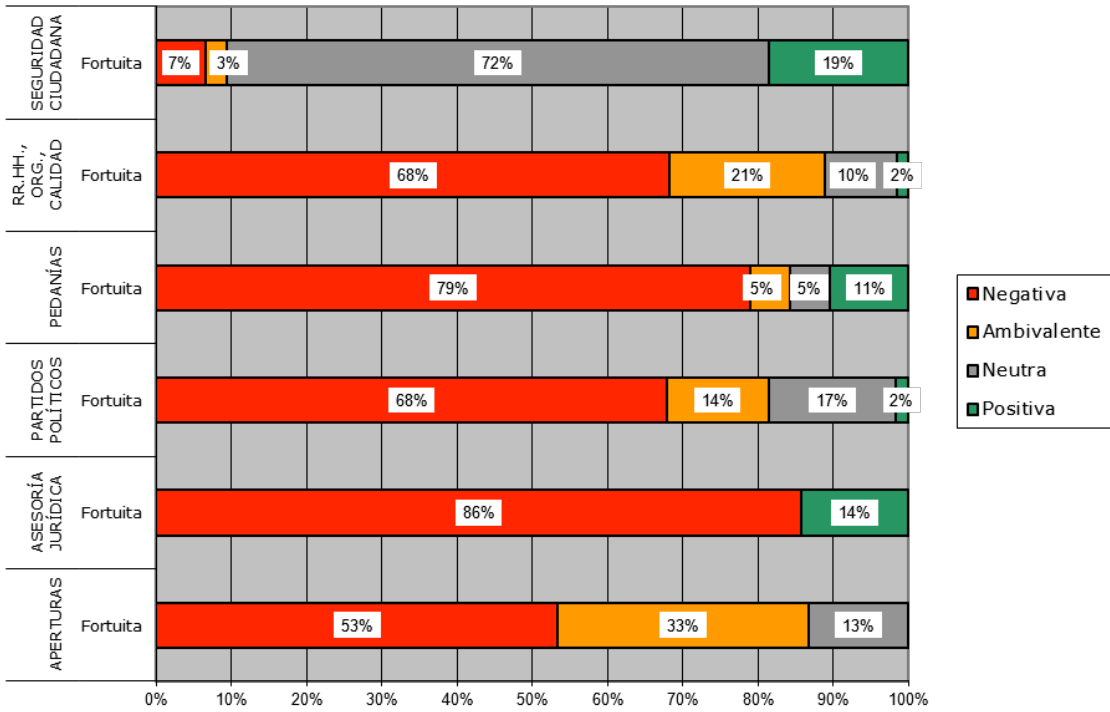


Gráfico 6. Temas previsibles y naturaleza de las noticias (1995-2007)




Gráfico 7. Temas programados y naturaleza de las noticias (1995-2007)

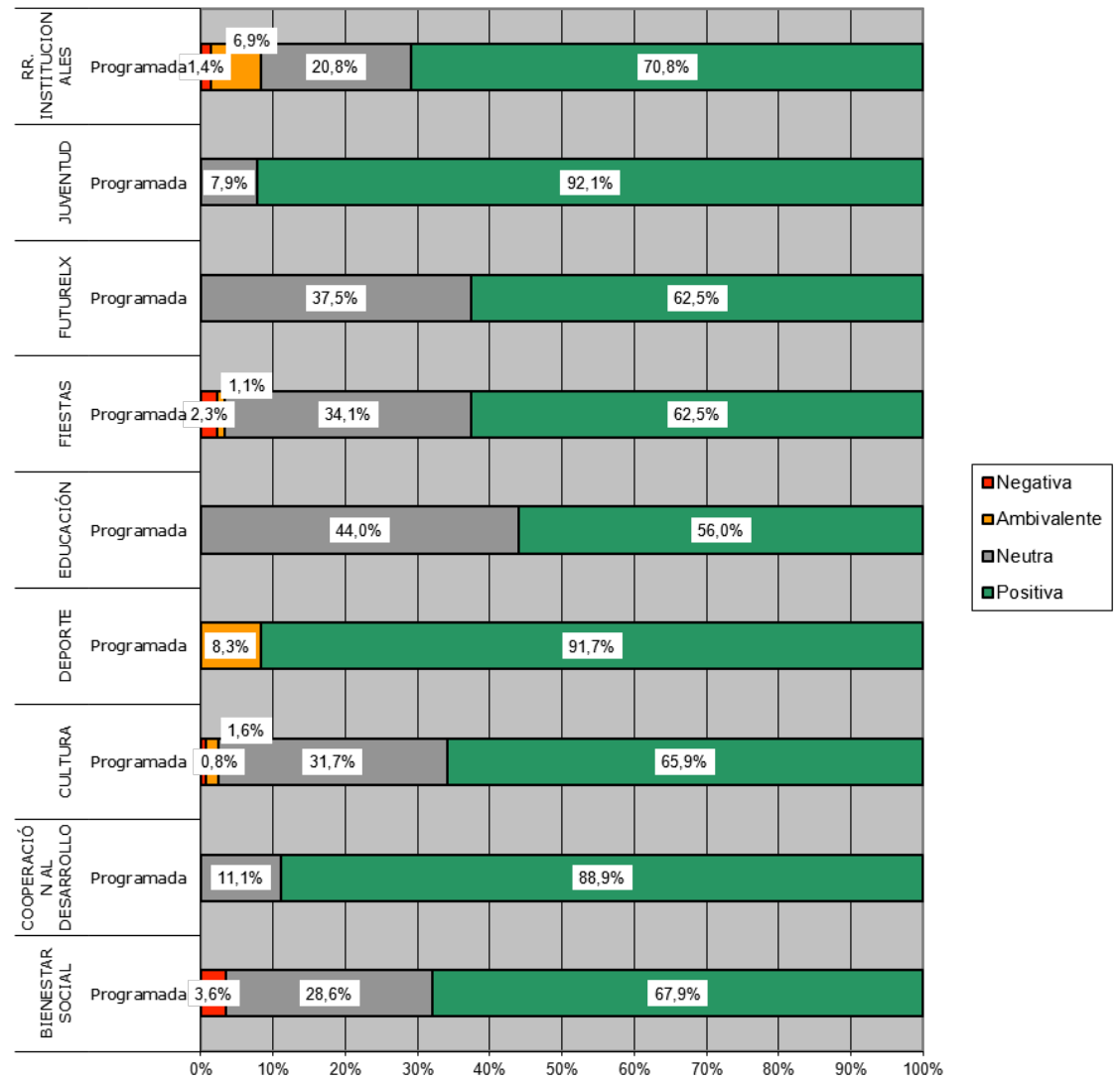

A partir de los gráficos 5, 6 y 7, se constata la correlación entre la irrupción de los temas y el tratamiento informativo: de manera que, en los temas que han sido identificados como fortuitos, el índice de noticias negativas y ambivalentes es muy superior al que se presenta en los temas previsibles y programados; de la misma forma que en los temas programados, el tratamiento informativo responde a un índice muy elevado de noticias neutras y positivas.

\section{Conclusiones}

Es indudable que la gestión de las relaciones informativas en los contextos democráticos representa la principal función comunicativa que asumen los dife- 
rentes niveles administrativos. Esta cuestión está relacionada con la premisa fundamental de la obligación administrativa de informar a los ciudadanos de determinadas decisiones, iniciativas o acuerdos alcanzados en las estructuras municipales, que les influyen de manera directa o bien pueden llegar a afectarles. La relación profesionalizada con los medios de comunicación social a partir de las estructuras pertinentes se erige como condición indispensable para propiciar sobre las organizaciones públicas un estado favorable a sus objetivos y estrategias a medio y largo plazo. Los medios de comunicación local interpretan la realidad social y política mediante la agenda temática: un conjunto de temas (issues) que el medio recopila con la intención de planificar, de forma genérica, su cobertura informativa para un periodo determinado. Así, la forma en que los aparatos informativos construyen la realidad social y política municipal a partir del contenido propuesto en la agenda temática, no es una operación ni inocente ni casual.

Tras el estudio que hemos efectuado, apuntamos la necesidad de que las instituciones municipales tomen conciencia de la trascendencia que pueden llegar a alcanzar determinados mensajes orientados a la ciudadanía, a través de los medios de comunicación social. Un seguimiento pertinente y constante del tratamiento y contextualización de los temas municipales por parte de sus estructuras comunicativas, permitirá confirmar la idoneidad de los discursos públicos desarrollados por los miembros del equipo de gobierno, la ausencia de contradicción en los mismos, así como pulsar la actuación de las fuerzas opositoras en determinados ámbitos. Una mediación informativa efectiva por parte de los gabinetes de comunicación, propiciando información programada, controlando la previsible y estableciendo estratégicas pro-activas preventivas para los hechos fortuitos, únicamente se conseguirá si éstos actúan bajo los parámetros de la transparencia, la equidad en su relación con los diferentes medios, la accesibilidad y la credibilidad como fuente informativa. Parece pertinente que tales estructuras comunicativas se doten de herramientas de evaluación análogas a la realizada en esta propuesta, adaptada a las variables contextuales de cada ente local.

Nuestro trabajo es una aproximación exploratoria a la realidad de lo municipal a partir de la agenda temática construida por un sólo medio de comunicación local. Sería posible, en este sentido, comparar las agendas temáticas de varios medios para establecer patrones comunes o diferentes en la construcción de las agendas temáticas municipales.

Esta agenda de temas relacionados con la gestión político-administrativa local podría utilizarse desde diferentes niveles de interpretación: en primer lugar, bajo la ya consolidada formulación de la agenda setting que nos permite configurar un triángulo con tres vértices: el análisis de la agenda mediática, agenda pública y agenda política; en segundo lugar, la comparación de las agendas temáticas entre diferentes municipios, como unidades de análisis, representaría otra vía de desarrollo: es posible analizar municipios con el mismo color políti- 
co, de manera que podamos constatar si los temas municipales más recurrentes coinciden de unos municipios a otros; o bien, si a partir de la selección de determinados municipios que poseen distinto color político, existen diferencias sustanciales en la construcción de las agendas temáticas.

El desarrollo de cualquiera de estas líneas de investigación serían aportaciones muy enriquecedoras que permitirían avanzar en el estudio de la comunicación pública municipal y complementar la propuesta que hemos realizado en nuestro trabajo.

\section{Referencias bibliográficas}

Abril, Gonzalo (1997). Teoría general de la información. Madrid: Cátedra.

Almansa, Ana (2004). Historia de los gabinetes de comunicación en España. En: Revista Historia y Comunicación Social, nº 9. pp. 5-21.

Almansa, Ana (2005). Relaciones públicas y gabinetes de comunicación. En: Anàlisi $\mathrm{n}^{0}$ 32. pp. 117-132.

Armentia, Ignacio y Caminos, Jose María (1998). La información. Redacción y estructuras. Bilbao: Universidad del País Vasco.

Álvarez, Tomás y Caballero, Mercedes (1999). Vendedores de imagen. Los retos de los nuevos gabinetes de comunicación. Barcelona: Paidós (Colección Papeles de Comunicación).

Bardin, Laurence (1986). Análisis de contenido. Madrid: Ediciones Akal.

Bel Mallén, José Ignacio (2004). La comunicación externa en las organizaciones: en Bel Mallén, José Ignacio (coord.). Comunicar para crear valor. La dirección de comunicación en las organizaciones. Navarra: Eunsa.

Casasús, José María (1988). Iniciación a la periodística. Manual de Comunicación escrita y Redacción Periodística Informativa. Barcelona: Teide.

Castillo, Antonio y Almansa, Ana (2001). El gabinete de comunicación en el ámbito local. En López Lita, Rafael (coord.). La prensa local y la prensa gratuita. Castellón: Publicacions de la Universitat Jaime I.

D’Adamo, Orlando y otros (2007). Medios de comunicación y opinión pública. Madrid: Mc Graw Hill.

Dearing, James y Rogers, Everett (1996). Agenda-Setting. Thousand Oaks: CA. Sage.

Díez Lobo, Jesús (2004). La información de las entidades locales. En Bel Mallén, José Ignacio (coord.). Comunicar para crear valor. La dirección de comunicación en las organizaciones. Navarra: Eunsa. 
Diezhandino, Pilar (2007). Periodismo y poder : políticos, periodistas y ciudadanos voluntariamente desinformados. Madrid: Pearson Prentice Hall.

Gomis, Lorenzo (1991). Teoría del periodismo: cómo se forma el presente. Barcelona: Paidós Ibérica.

Grunig, James y Hunt, Todd (2000) [1984]. Dirección de Relaciones Públicas. Barcelona: Gestión 2000.

Krippendorf, Klaus (1990). Metodología de análisis de contenido: teoría y práctica. Barcelona: Paidós Comunicación.

Lucas, Antonio (1997). La comunicación en la empresa y en las organizaciones. Barcelona: Bosch Comunicación.

McCombs, Maxwell. E. y Shaw, Donald L. (1972). The Agenda-Setting function of mass media. En: Political Opinion Quarterly, n ${ }^{\circ} 36$. pp. 176-187.

Monzón, Cándido (1990). La Opinión Pública: teorías, concepto y métodos. Madrid: Tecnos.

Monzón, Cándido (2006). Opinión pública, comunicación y política. Madrid: Tecnos

Ramírez, Txema (1995). Gabinetes de comunicación: funciones, disfunciones e incidencia. Barcelona: Bosch.

Reglamento de Organización Administrativa del Ajuntament d'Elx (2003-2007). Texto impreso.

Ruiz Vivo, Jose Antonio (2003). Periodismo Institucional: comunicación Administración pública-ciudadano. En Fernández, Manuel, Sierra, Javier y Valero, Julián (coords). Nuevos retos en el horizonte de las Administraciones. Universidad de Murcia.

Villafañe, Justo (1999). La gestión profesional de la imagen corporativa. Madrid: Pirámide.

Wimmer, Roger y Dominick, Joseph (1996). La investigación científica de los medios de comunicación. Una introducción a sus métodos. Barcelona: Colección Bosch Comunicación.

Wolf, Mauro (1987). La investigación de la comunicación de masas. Barcelona: Paidos.

Wolf, Mauro (1994). La investigación de la comunicación de masas. Crítica y perspectivas. Barcelona: Paidós, Colección Instrumentos de Comunicación. 


\section{Referencia de este artículo}

Campillo Alahama, Concepción (2012). La gestión estratégica de la información municipal. Análisis de temas, su tratamiento e irrupción en el Ayuntamiento de Elche (1995-2007). En: adComunica. Revista Científica de Estrategias, Tendencias e Innovación en Comunicación, $\mathrm{n}^{0} 3$. Castellón: Asociación para el Desarrollo de la Comunicación adComunica, Universidad Complutense de Madrid y Universitat Jaume I, 149-170. DOI: http://dx.doi.org/10.6035/21740992.2012.3.10 